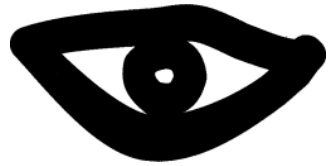

\title{
Relações família-universidade, rendimento acadêmico e gênero no ensino superior brasileiro
}

\author{
Suely A. do N. Mascarenhas* \& Antônio Roazzi** \\ *Universidade Federal do Amazonas (Brasil), **Universidade Federal de Pernambuco (Brasil)
}

\begin{abstract}
Resumo
Considera-se a relevância do papel da família no desenvolvimento e sucesso escolar dos estudantes. Participaram 1489 estudantes do sexo masculino e feminino, matriculados em duas universidades brasileiras. Das análises observou-se a existência de três dimensões: "Confiança na capacidade e recompensas", "Desejo de mobilidade social" e "Estrutura da universidade e rendimento". Foi evidenciada (a) a influência das percepções familiares sobre a conduta de estudos impactando sobre o rendimento acadêmico dos estudantes, (b) a diferença de sexo com relação às expectativas familiares associadas à conclusão do curso universitário e (c) a ascensão social, favorável aos estudantes do sexo masculino.

Palavras-chave: Relações família-universidade, Ensino superior, Rendimento acadêmico, Avaliação psicológica.
\end{abstract}

O sucesso e o desenvolvimento pessoal em sentido amplo é largamente influenciado pelas relações familiares. Família é um conceito que tem evoluído sendo entendido como família biológica e social. A biológica é a tradicional pais, irmãos, tios, avós, etc. A social abrange a vizinhança, a igreja, o clube, a cidade, o país e a humanidade. Em 1948 na Declaração dos Direitos Humanos, a ONU nomeou a humanidade de família humana. Daí a co-responsabilidade pelo bem comum na sociedade que acaba sendo a família alargada de todos.

Considerando o ponto de vista sociológico, o essencial em uma família é a organização conjunta do espaço de habitação baseado na responsabilidade mútua para assegurar o sustento, a existência de valores e normas comuns assim como laços emocionais estreitos.

Deferentes trabalhos e pesquisas consultados demonstraram que na perspectiva pedagógica a família é importante especialmente como lugar de socialização primária das pessoas e por suas funções concomitantes ou complementares em interação com todos os processos organizados socialmente de educação, formação e instrução Aries, 2006;Barca, 1982; Brasil 1988; Chickring \& Reisser, 1993; Mascarenhas, 2004). As pesquisas têm demonstrado até o momento que a influencia da família continua sendo decisiva para o desenvolvimento do sentimento de autovalor, de identidade, de motivação e autoconceito, bem como para os êxitos e fracassos nos contextos escolares em todas as esferas (Schaub \& Zenke, 2001).

Neste trabalho iremos nos referir ao conceito de família biológica aquela responsável pelas atividades de subsistência, educação e desenvolvimento humano desde a concepção até o ingresso e conclusão das diversas modalidade de ensino formal. Entendendo como funções da família as econômicas, de cuidado social, economia doméstica bem como as relações emocionais entre os membros no cotidiano e nos tempos de lazer.

Buscamos através deste trabalho estudar a relação família-universidade e seus efeitos sobre o rendimento acadêmico, e também as variáveis contextuais que exercem influencia sobre a conduta e a motivação dos estudantes pois, de acordo com a literatura especializada, o resultado da aprendizagem é afetado, condicionado e determinado por variáveis que exercem influencia sobre a qualidade do conhecimento construído pelos estudantes, e o apoio familiar é uma dimensão importante neste contexto. Esperamos assim, contribuir com a ampliação da oferta de informações que possam ser utilizadas pela gestão acadêmica, no sentido de criar projetos, programas e ações que valorizem e considerem a importância das relações família-universidade de modo a impactar na melhoria dos indicadores de ensino-estudo-aprendizagem e rendimento acadêmico positivo.

Está estabelecido na atual Constituição Brasileira, em seu capítulo III - Da Educação, Da Cultura e do Desporto, seção I - Da Educação, que: "A Educação direito de todos e dever do Estado e da família, será promovida e incentivada com a colaboração da sociedade, visando ao pleno desenvolvimento da pessoa, seu preparo para o exercício da cidadania e sua qualificação para o trabalho" (Constituição Brasileira, 1988). Este princípio configura-se como dever da família a orientação que parte do ambiente familiar para o social. Para Ariés (2006), uma das funções da família é a de proteção dos seus membros, pois a família proporcionará a base para que os mesmos desenvolvam sua autoconfiança e sua autonomia para a vida em sociedade. Para quem não está preparado, a vida longe dos familiares pode ser muito desafiadora, sendo assim, a família deve instruir e preparar o indivíduo para a vida fora do ambiente familiar.

Podemos ainda considerar a família em suas diversas constituições dentro da sociedade atual, na qual vem assumindo diversos formatos para além do núcleo tradicional pais/filhos. Dentro do contexto acadêmico, podemos identificar algumas dessas novas configurações, como por exemplo, as mulheres que são mães de família e também universitárias, os pais de família universitários, além de jovens universitários que se encontram longe de seu contexto familiar.

Toda essa variação de contextos familiares gera relações diferenciadas entre os núcleos familiares e o ambiente acadêmico, e também, do mesmo modo, interfere na qualidade, benefícios e orientação educacional que essa relação proporciona ao indivíduo que acaba de ingressar na universidade. 
Analisando outros estudos sobre o tema, a informação que se encontra é que quando se trata da importância da família para os processos educativos se pensa prioritariamente, e muitas das vezes exclusivamente, no acompanhamento das atividades escolares dos estudantes, e da presença da família na escola, interagindo com as equipes educacionais (reuniões, participação semanal nas escolas, entre outras que levam a família a interagir mais vezes nas instituições). Na universidade esta conjectura fica ainda mais evidente, parece haver um pressuposto implícito de que a família perde sua autonomia e importância na vida educacional de estudantes universitários (Mascarenhas \& Gutierrez, 2011).

Atualmente, as Universidades têm recebido a contribuição acadêmica da família de duas maneiras: construindo o currículo (e o sucesso escolar) implicitamente com base no capital cultural similar herdado pelos alunos, isto é, com base nos hábitos ou sistema de disposições cognitivas adquiridas, e na socialização primária, ou educação doméstica, o que supõe afinidade cultural entre escola e família. Desta forma, a relação entre família e escola implica num diálogo no qual aconteça uma constante e ativa procura de significado, que possa gerar uma escuta ativa, reforçada pelo desenvolvimento de uma atitude empática, e pelo esforço para compreender o ponto de vista do outro (Rocha, 2010.)

Logo, a instituição que acolherá o novo estudante necessita, em grande parte, do apoio direto e sistemático da família que investe nos seus entes durante os anos de escolarização formal, compensando tanto dificuldades individuais quanto deficiências escolares. Com a participação e o acompanhamento familiar no processo de estudo-aprendizagem, o estudante fortalece sua confiança pessoal percebendo que seus familiares desejam o seu sucesso, apóiam seu esforço e acreditam na sua capacidade e potencial para o sucesso acadêmico e profissional (Mascarenhas \& Gutierrez, 2008; Mascarenhas \& Gutierrez, 2011; Mascarenhas, Gutierrez, Lira, Barca, Barroso \& Oliveira, 2013; Mascarenhas, Peluso, Oliveira, Aguiar, Gutierrez \& Barca, 2013).

\section{MÉTODO}

\section{Participantes}

Participaram voluntariamente da pesquisa "Avaliação dos enfoques de aprendizagem e de variáveis cognitivas e contextuais interferentes no rendimento de universitários do ensino superior do Amazonas e de Rondônia", processo 575.723/2008-4 n=1489 estudantes matriculados em diversos cursos de graduação da Universidade Federal do Amazonas (UFAM) e da Universidade Federal de Rondônia (UNIR). Sendo os matriculados nas unidades da UFAM e UNIR, oriundos das seguintes localidades com respectivas porcentagens: Humaitá 21,6\%, Manaus, 18,3\%, Itacoatiara 9\%, Coari 13,4\%, Parintins 4,8\%,Benjamin Constant 16,8\%, Ariquemes 4,3\%, Porto Velho, 2,1\%, Rolim de Moura, $1,1 \%$, Guajará Mirim 1,7\%, Cacoal 4,1\%, Ji-Paraná $3,4 \%$.
As idades dos participantes variam entre 18 anos e 64 anos, $\mathrm{M}=23,42 \mathrm{DP}=6,43$, sendo $61,9 \%$ são do sexo feminino e $38,1 \%$ do sexo masculino.

Quanto à etnia, $72,5 \%$ não declararam, $14 \%$ consideram-se pardos, 9,5\% brancos, 2,7\% negros e $1,2 \%$ indígenas.

Dos matriculados na UNIR foram $\mathrm{n}=249$ estudantes, sendo $58,2 \%$ do sexo feminino e $41,8 \%$ do sexo masculino. No que se refere à identidade étnica $14,9 \%$ consideram-se brancos, $11,2 \%$ negros, $13,3 \%$ pardos, $10,4 \%$ indígenas e $50,2 \%$ não declararam sua identidade étnica.

No que se refere aos indicadores de rendimento acadêmico constatamos que a maior incidência encontra-se na faixa média, na qual a nota varia de 5.1 a 7.0, sendo que esta média é representada por 437 estudantes, ou seja, 29,3\% dos pesquisados, já os demais estudantes, 395 destes ou $26,5 \%$, possuem alto rendimento com média de 7.1 a 8.0 , no total são 368 ou $24,7 \%$ dos estudantes que possuem baixo rendimento que varia de 0 a 5.0 e apenas 289 estudantes ou $19,4 \%$ possuem rendimento acima de 8.0

\section{Instrumento}

Os dados apresentados neste texto foram obtidos a partir da aplicação do Questionário relações cognitivas e contextuais (Mascarenhas \& Gutierrez, 2008), dimensão família-universidade com 10 itens organizados em formato Likert de 5 pontos variando entre: 1. Totalmente em desacordo e 5. Totalmente de acordo a estudantes do ensino superior. $\mathrm{O}$ instrumento foi elaborado a partir de estudos e pesquisas anteriores de suas autoras com o objetivo de contribuir para a construção de um instrumento de avaliação psicológica neste domínio da educação formal e que foi validado com a realização da pesquisa em pauta. Tendo apresentado indicadores de fiabilidade que o qualificam para medir o que se propõe Alpha de Cronbach acima ,70.

\section{Procedimentos de coleta, tratamento e análise de dados}

O questionário foi aplicado por equipe de colaboradores orientados pela pesquisadora responsável nas unidades da UFAM e UNIR. Os estudantes responderam voluntária e anonimamente ao instrumento observando procedimentos éticos internacionais, de modo individual em horário de aula previamente agendado com os professores após serem informados dos objetivos da pesquisa. O tempo de resposta variou entre 5 e 15 minutos, $\underline{M}=10 \mathrm{~min}$.

Após a coleta dos dados os mesmos foram enviados ao LAPESAM, Unidade da UFAM, IEAA, Humaitá via malote ou correios sedex onde após a conferência e organização receberam tratamento estatístico com apoio do programa SPSS de acordo com os objetivos da pesquisa. Foram realizadas diversas análises estatísticas, todavia pelas características deste trabalho, registramos correlação entre os fatores da escala e o rendimento acadêmico. 


\section{RESULTADO E DISCUSSÃO}

A partir de análises multidimensionais foi observada a existência de três dimensões: "Confiança na capacidade e recompensas", "Desejo de mobilidade social" e "Estrutura da universidade e rendimento". Foi evidenciada também (a) a influência das percepções familiares sobre a conduta de estudos impactando sobre o rendimento acadêmico dos estudantes, (b) a diferença de sexo com relação às expectativas familiares associadas à conclusão do curso universitário e (c) a ascensão social, favorável aos estudantes do sexo masculino.

Estes resultados apontam na direção da existência de uma influência das relações família universidade sobre o rendimento acadêmico no ensino superior, o que confirma a tendência de resultados de pesquisas no âmbito da educação formal publicadas, demonstrando a importância do acompanhamento e apoio familiar para o sucesso acadêmico no contexto universitário (Mascarenhas e Col, 2013 $3^{\mathrm{a}}, \mathrm{b}$ ).

Por outro lado a pesquisa ao revelar diferença nas representações de sexo no que se refere à ascensão social favorável aos estudantes do sexo masculino confirma a tendência de vantagem psicológica masculina com relação às percepções sobre oportunidades de sucesso social demonstrada historicamente pela literatura especializada. Quanto à validade do instrumento, o estudo revelou sua validade estatística, confiabilidade acima ,70.

Conforme observado na Tabela 1 , da análise fatorial Método de extração: Análise de componentes principais, Método de rotação: Normalização Varimáx com Kaiser, obteve-se indicadores psicométricos aceitáveis. KMO .758, Alpha de Cronbach .711.

Foram encontrados três fatores, sendo:

Fator 1. Confiança na capacidade e recompensas (itens 5, 4, 6 e 7), valor próprio 2,419, variância $24,187 \%$.

Fator 2. Desejo de mobilidade social (itens 8, 9 e 10), valor próprio 1,850, Variância 18,500\% e

Fator 3. Estrutura da universidade e rendimento (itens 1,2 e 3), valor próprio 1,538 e variância $15,382 \%$. Variância total 58,069\%

Da ANOVA realizada, ficou demonstrada a influencia das percepções familiares sobre a conduta de estudos impactando sobre o rendimento acadêmico dos estudantes $p \leq .001$.

Foram encontradas diferenças significativas com relação às expectativas familiares associadas à conclusão do curso universitário e a ascensão social, favoráveis aos estudantes do sexo masculino $p \leq .001$.
Tabela1.

Estrutura fatorial Escala Relações Família - Universidade (Amazonas e Rondônia-Brasil)



Conclui-se (i) que existe influência das relações família escola sobre o rendimento acadêmico; (ii) que existe diferença de gênero no que se refere à ascensão social e (iii) constatou-se a validade estatística do instrumento utilizado no que se refere à avaliação do fenômeno em causa. 
A continuidade de pesquisas e estudos na área em diferentes contextos sociais e educativos poderá contribuir, a exemplo da pesquisa em pauta, com o aporte de novas informações sistematizadas que possam apoiar a proposição de políticas educacionais de fortalecimentos das relações família-universidade.

Por outro lado, as novas informações aportadas podem apoiar a proposição de políticas públicas que considerem as diferenças de gênero no ensino superior.

Agradecimento: os autores agradecem o apoio financeiro do CNPq.

\section{REFERÊNCIAS}

Aries, P. 2006). História social da criança e da família. Rio de Janeiro: Zahar.

Barca, A, (1982). Psicopatologia familiar y dificultades escolares, pág. 95-107, In. Barca, A. Bellón, V, Del Amo, J, Dominguez Rey, J.L., Pinillos, J. L \& Carballo, J. R. La Familia en la educación, La Coruña, Espanha, Editorial Humanitas.

Brasil. (1988).Constituição da República do Brasil, Brasília, Senado Federal.

Chickring, A. \& Reisser, L. (1993). Educação e identidade. San Francisco: Jossey- Bass Publishers.

Mascarenhas, S. (2004). Avaliação dos Enfoques de Aprendizagem dos Alunos do Ensino Médio do Estado de Rondônia. Tese de Doutorado, Universidade de La Corunã Espanha.

Mascarenhas, S.; Gutierrez, D.M.D. (2008). Escala de Avaliação de Dimensões Contextuais $e$ Cognitivas para Estudantes Universitários, Pertencente ao projeto: Avaliação dos enfoques de aprendizagem e de variáveis cognitivas e contextuais interferentes no rendimento de universitários do ensino superior do Amazonas e de Rondônia (Edital 55/2008 - CNPq), não publicada.

Mascarenhas, S.; Gutierrez, D. M. D. (2011). Relações família-universidade no contexto amazônico. II Congresso Luso-Brasileiro de Psicologia da Saúde e I Congresso Ibero-Americano de Psicologia da Saúde. São Paulo: UNIMEP.

Mascarenhas, S. A. do N., Gutierrez, D.M. D., Lira, R., Barca, A. L., Barroso, F. \& Oliveira, A.M. G. de (2013a). Relações família-universidade e rendimento acadêmico de estudantes do ensino superior, pág.46-70. In. Mascarenhas, S. A. do N. (Coord.)Determinantes do Rendimento Acadêmico no Ensino Superior, São Paulo, Loyola.

Mascarenhas, S. A. do N., Peluso,M. L.A.,Oliveira, G. S., Aguiar, R.S. Gutierrez, D.M. D.,. \& Barca, A.L. (2013b). Relações família-escola e rendimento acadêmico no ensino superior, pág.82-97. In. Mascarenhas, S. A. do N. (Coord.) Determinantes do Rendimento e do Bem Estar Psicossocial em Contextos Educativos Formais, São Paulo, Loyola.

Rocha, H. Ma . P.(2010). Adolescente e Vínculo Parental: (Des)continuidade entre família e escola. Universidade de Aveiro, Lisboa.

Schaub, H. \& Zenke, K. G. (2001). Diccionario Akal de Pedagogía, Madrid, Akal Ediciones S.A. 